\title{
From Barcelona to Sicily: An Investigation on the Relationship Between Composition and Daylight in Squares
}

\author{
Marco Graziano ${ }^{1}$ | Judit Lopez-Besora ${ }^{2}$ | Gianluca Burgio ${ }^{3}$ | Antonio Isalgue ${ }^{4}$ | Isabel Crespo ${ }^{5}$ \\ Received: 2021-04-27 | Final version: 2021-07-26
}

\begin{abstract}
The perception and liveability of an urban space can greatly depend on the correct management of solar radiation. The practice of using daylight as a design tool to evaluate the environmental comfort is not very widespread for outdoors: however, the light analyses in the exterior places can allow an ideal reading of the architectural scenario in formal and functional terms. This research seeks affinities between the composition of public spaces and their illumination during the day, in order to understand which parameters, influence the visual and thermal comfort for the users. In this essay it is evaluated the distribution and trend of daylight physical data in the squares of Mediterranean cities. The survey focuses specifically on two rectangular squares (one Sicilian and one Catalan) with similar spatial characteristics, which were chosen for a comparative study. The four urban scenes of each square were photographed in three different time intervals: these images were processed by an experimental software that provided data on the perceived daylight in terms of luminance, standard deviation, and spatial contrast. The technical assessment of light in different times of the day, together with the morphological analyses of the places, provides a series of information on the environment that can be used for urban redevelopment works or as a support for the architectural composition of new spaces. This study therefore researches how spatial and lighting characteristics influence the level of habitability of square areas, the time spent there and how these indicators can be improved.
\end{abstract}

Keywords: Urban scene; daylight; visual comfort; urban morphology

Citation

\section{De Barcelona a Sicilia: relación entre la composición y la luz natural en las plazas}

Resumen

\begin{abstract}
La percepción y la habitabilidad del espacio urbano son aspectos muy relacionados con la radiación solar. Sin embargo, el análisis de la luz natural no suele utilizarse para evaluar el confort ambiental en espacios urbanos, a pesar de que dicho análisis lumínico proporciona una lectura excelente del escenario arquitectónico en términos formales y funcionales. En esta investigación se buscan conexiones entre la composición de los espacios públicos y la luz natural que permitan comprender qué parámetros influyen en el confort visual y térmico de sus usuarios. Concretamente, se evalúa la distribución y la tendencia de los datos físicos referentes a la luz natural en plazas situadas en ciudades mediterráneas. El estudio se enfoca en dos plazas rectangulares (una en Sicilia y otra en Catalunya) con características espaciales similares, en las que se realiza un estudio comparativo. Cuatro escenas de cada plaza fueron fotografiadas en tres intervalos de tiempo distintos: luego, las imágenes se procesaron mediante un software experimental que proporciona datos lumínicos en términos de luminancia, desviación estándar y contraste espacial. Esta evaluación técnica sobre la luz en diferentes momentos del día, junto al análisis morfológico de las plazas, proporciona una información acerca del ambiente exterior que es aplicable a trabajos de renovación urbana o como soporte para la composición arquitectónica de nuevos espacios. Los resultados explican cómo las características espaciales y lumínicas influyen en la habitabilidad de las plazas, el tiempo que se pasa en ellas y cómo mejorar sus indicadores.
\end{abstract}

Palabras clave: Escena urbana; luz natural; confort visual; morfología urbana

${ }_{1}^{1}$ Ph.D. Architect, Università degli Studi di Enna "Kore" (ORCiD: 0000-0002-3293-6810), ${ }^{2}$ Ph.D. Architect, Universitat Politècnica de Catalunya (ORCiD: 0000-0002-8659-9346, Scopus Author ID: 56156756500, WoS ResearcherID: $\underline{\text { - }}$ 1843-2017), ${ }^{3}$ Ph.D. Architect, Università degli Studi di Enna "Kore" (ORCiD: 0000-0002-0051- 2685, Scopus Author ID: 55556828200), ${ }^{4}$ Ph.D. in Physics, Universitat Politècnica de Catalunya (ORCiD: 0000-0002-4354-5831, Scopus Author ID: 7004080030, WoS ResearcherID: M-2459-2014), ${ }^{5}$ Ph.D. Architect, Universitat Politècnica de Catalunya (ORCiD: 0000-0002-2422-0935). Contact e-mail: judit.lopez.besora@upc.edu 


\section{Introduction}

A good environmental design for daylight conditions allows the user to experience the public space in the best possible way. Regarding the exterior spaces, William M.C. Lam states that "appropriate lighting for such spaces must therefore reveal and emphasize that environmental information which satisfies the biological needs for safe movement, orientation, security, pleasure, relaxation, stimulation, etc." (Lam, 1992, p.29). The study presented here explores the relationship between the architectural composition of the squares and the way in which the observer perceives their illumination during the day. The squares can be identified as formal and functional irregularities within the city - a unicum inside the urban continuum (Roseti, 1985) - and they are the mirror of the spatial dynamics and socio-cultural changes of living in the inhabited centres, representing the urban exception from which the city develops or the cause for which the urban fabric is interrupted 1 . These places will always represent a point of reference within cities, so it is necessary to give them a strong inclusive connotation, starting with a good reading of the architectural context. In this regard, the study of the visual scene can be fundamental: it is that portion of space observed by the user who moves or stops in the city environment. The way in which the visual scene is composed, together with other important factors such as the latitude of the place, the day of the year, the viewing time, and the cardinal direction of the gaze, can radically change the characteristics of the perceived daylight in the urban space.

The analysis proposed in this essay focused specifically on the visual scenes of the Mediterranean city squares, since it was necessary to sectionalize the case studies and results as much as possible, considering the high variability of climatic conditions and the different nature of the solar contribution in our continent. Using an experimental software developed during a PhD research work (LopezBesora, 2015), it was possible to process a series of photographic images (which simulate the visual scene) with HDR technology, allowing to obtain data on luminance, standard deviation and spatial contrast (Rockcastle and Andersen, 2014). The experimental software used in this study is similar to other commercial ones that generate luminance maps from digital pictures. Unlike them, it also considers other light parameters such as the mentioned above. Besides, the processing permits the definition of specific zones defined by the user and therefore, the distribution of light in the urban scene. An evaluation of this type makes it possible to find correspondences between the spatial composition of the squares and daylight measured with real data ${ }^{2}$. Being able to carry out the investigation both in Barcelona and in Sicily, the images of different squares in the Catalan city and in the Italian region have been processed. In this way, the analysis of the single public space and the comparison between the various cases made possible some reflections on the perception and visual comfort in the environments; the data found also permit to highlight specific compositional characteristics of the squares and to suggest some design actions that can guarantee optimal management of solar radiation in these spaces. The hypothesis of the survey is that there may be common characteristics between the visual scenes analysed in the squares of Sicily and Barcelona in terms of their appearance and type of light. The objective is to establish a formal and visual comparison between two squares that share a similar geographic environment, while checking that the daylight pattern created in the corresponding visual scenes is comparable.

\footnotetext{
${ }^{1}$ Squares are "cause and effect" of social transformations in the population centres (Tuzi, 1990) (Portoghesi, 1990): historically, in Europe, the creation of squares as an urban fulcrum conditioned the development of the entire city, until the nineteenth century when they began to appear as a pause in the urban fabric with the aim of allowing the city to breathe (Sitte, 2015).

2 "If visual characteristics of daylight, such as contrast and spatial compositions, can be objectively measured, we can contribute to a more holistic analysis of daylight architecture with metrics that complement existing illumination and comfort-based performance criteria" (Rockcastle \& Andersen, 2014).
}

ACE, 16 (4.7) CC BY-ND 3.0 ES | UPC Barcelona, España | From Barcelona to Sicily: An Investigation on the 2 Relationship Between Composition and Daylight in Squares. DOI: http://dx.doi.org/10.5821/ace.16.47.10504 


\section{Methodology}

\subsection{Planar shape and geometric classes}

Before taking the photographic shots to start this technical study, a precise formal category of open public spaces had to be selected to adopt a uniform analysis methodology. The first typological feature of squares is linked to their planar form, which gives valuable information on the way in which it is grafted into the urban fabric and the underlying compositional principles of its design. In this regard, a brief classification of the squares from the point of view of planar geometry was initially necessary, highlighting the opening or closing of these spaces according to the distribution of solids and voids in the plan.

The ways in which the squares can be classified from the planimetric point of view are manifold. Sitte (2015), for example, had divided these spaces according to their origin within the urban fabric, which could be orthogonal, triangular, or radial: for the Austrian architect, the other compositions were generated by mixing these three models. Roseti (1985) opted for a more complex categorization considering the following formal aspects: regularity, irregularity, symmetry, asymmetry, opening, closing, emptiness or filling with different elements. Another proposal is that of Wolfrum (2014), who has created a very interesting and articulated classification that considers not only the basic shape, but also the size of the area, the morphological qualities, together with the time of origin and the performative potential.

The categorization that was used for the survey considers the geometric shape and the size of the open space, returning the consequent and different perspective views. This division showed the difficulty to analyse some urban scenes resulting from the complex geometry of the squares, as when, studying the perspective effect, it is not easy to recognize the spatial limits on the vertical axis of vision. For this reason, the analysis was conducted on those spaces with the most classic of planar geometries, the rectangular one.

The use of a rectangular shape for the main meeting place of the city has very ancient origins. In the ancient city-palace of Sargon there was already a network of rectangular patios around which the city developed and from which you could access the main buildings; in other ancient buildings such as the Cretan one at Knossos, the rectangular square was the regulating element within the labyrinthine mesh. The rectangular model certainly consolidated in the Greek period and then in the Roman one (Romano, 2015). In the first case, through the configuration of many agorà, especially those obtained from a grid with orthogonal blocks: a peculiar case was that of the coastal city of Miletus, where two neighbouring squares (the largest main and the smallest commercial) were located at fulcrum of the city representing its socio-functional centre. In the Roman period the figure of the square is associated with the forum, the main public place and social, political, and religious expression of the community.

The typical shape of the forum was precisely the rectangular one, a geometry deriving from the tracing of the Roman castrum, and which assumed precise dimensional peculiarities based on the desired spatial effects. The position of the forum within the urban grid could be either barycentric or peripheral: a magnificent example belonging to the second category is the forum of Pompeii, an elongated rectangular layout dominated to the north by the capitolium (Tuzi, 1990) (Portoghesi, 1990). Among the reasons that pushed these civilizations to adopt this planar form are the excellent spatial control, an adequate sensation of depth and the possibility of orienting the main buildings according to certain solar exposures: these principles are the same for which this geometry was adopted in successive periods and still today.

ACE, 16 (47) CC BY-ND 3.0 ES | UPC Barcelona, España | From Barcelona to Sicily: An Investigation on the Relationship Between Composition and Daylight in Squares. DOI: http://dx.doi.org/10.5821/ace.16.47.10504 
That said, focusing the study on the rectangular shapes only, the boundary between the flat and elevated development of the square surfaces was immediately identifiable. So, once the studio was set up on those sites, it had to be identified which spaces in Barcelona and Sicily could be the protagonists of the investigation. First, a list of different rectangular squares in the two geographic contexts was created: some of them have been drawn in planimetry to understand the relationship between the full and empty spaces of the place with respect to the urban grid. Figures 1 and 2 show some planimetric diagrams of the squares identified in Barcelona and Sicily: the image shows the names of the places, the planar extension (approximate value) and the degree of opening/closing of the urban space. Regarding the opening or closing of the square towards the urban fabric, the spaces have been divided into four categories following the indications of Roseti (1985): open, closed, semiopen and semi-closed. In summary, this classification considers the degree of interaction - directly or at a distance - between the building curtain and the area of the square, and the distribution percentage of the buildings facing along the perimeter.

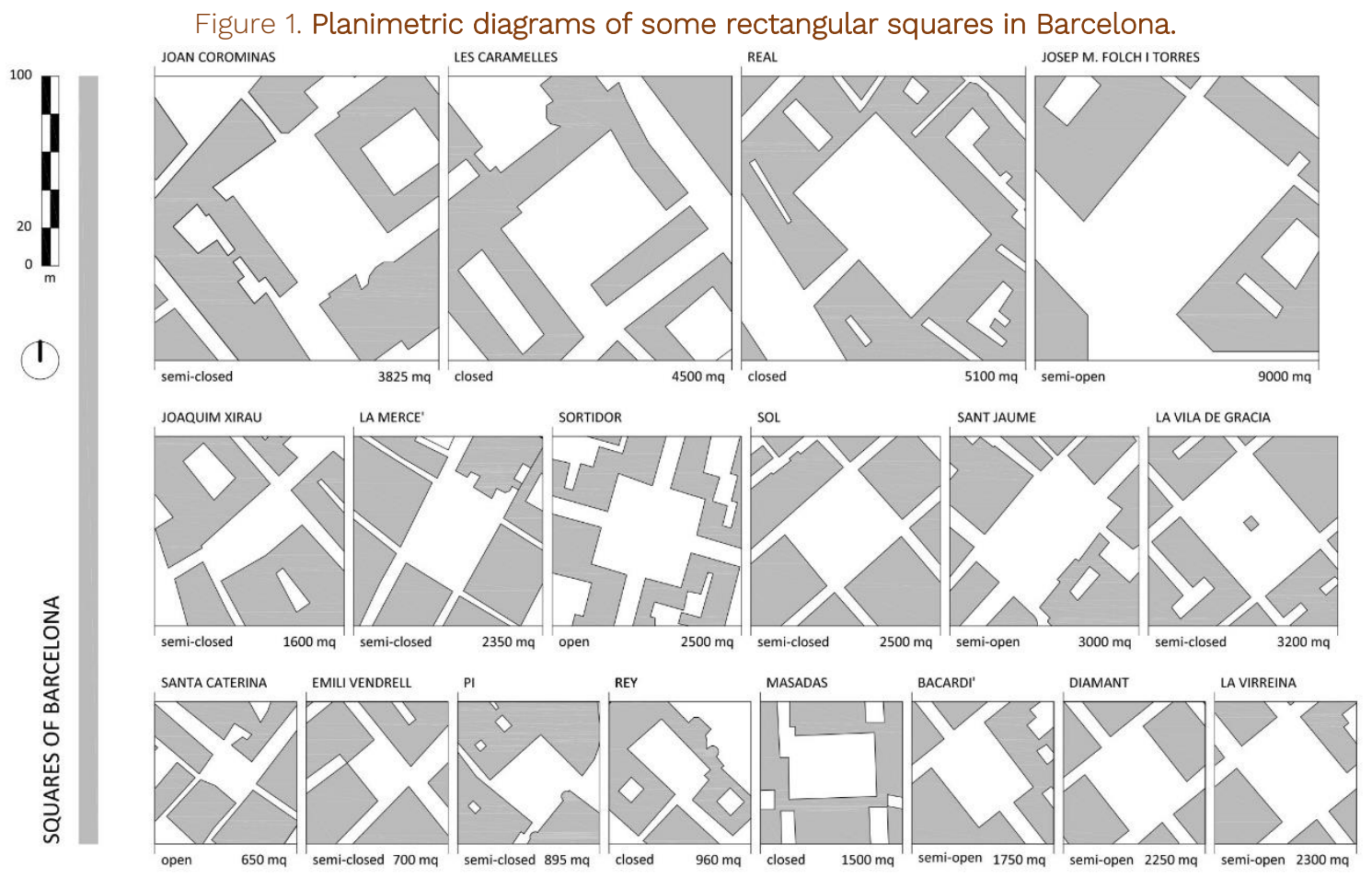

Source: Graphic elaboration by the author.

Note: The names, planar dimensions, and spatial opening/closing are indicated in the image

The relationship between the size of the square and the contribution of daylight cannot stop at the analysis of the floor plan alone. A fundamental aspect is the study of the elevations and their relationship with the open space: "Their dimensions and proportions, their multiple and contradictory uses, the design of their facades and the way they mesh with the urban fabric are the keys to understanding their essential reasons for being" (Rubert de Ventós, 2007, p.59) (Mancuso et al., 2007). This type of investigation began already in medieval times, when the choice of the planar and altimetric dimensions of the surfaces aimed to surprise the visitor to the square. For this reason, the open space was not very extensive, while the facing buildings (especially the religious ones) showed a very important height, hiding the sky within the visual field. Furthermore, in many cities, the rectangular square represented the geometric rule within an urban grid that developed organically, as well as being the source of light distribution in the various contiguous road arteries.

ACE, 16 (47) CC BY-ND 3.0 ES | UPC Barcelona, España | From Barcelona to Sicily: An Investigation on the 
Figure 2. Planimetric diagrams of some rectangular squares in Sicily

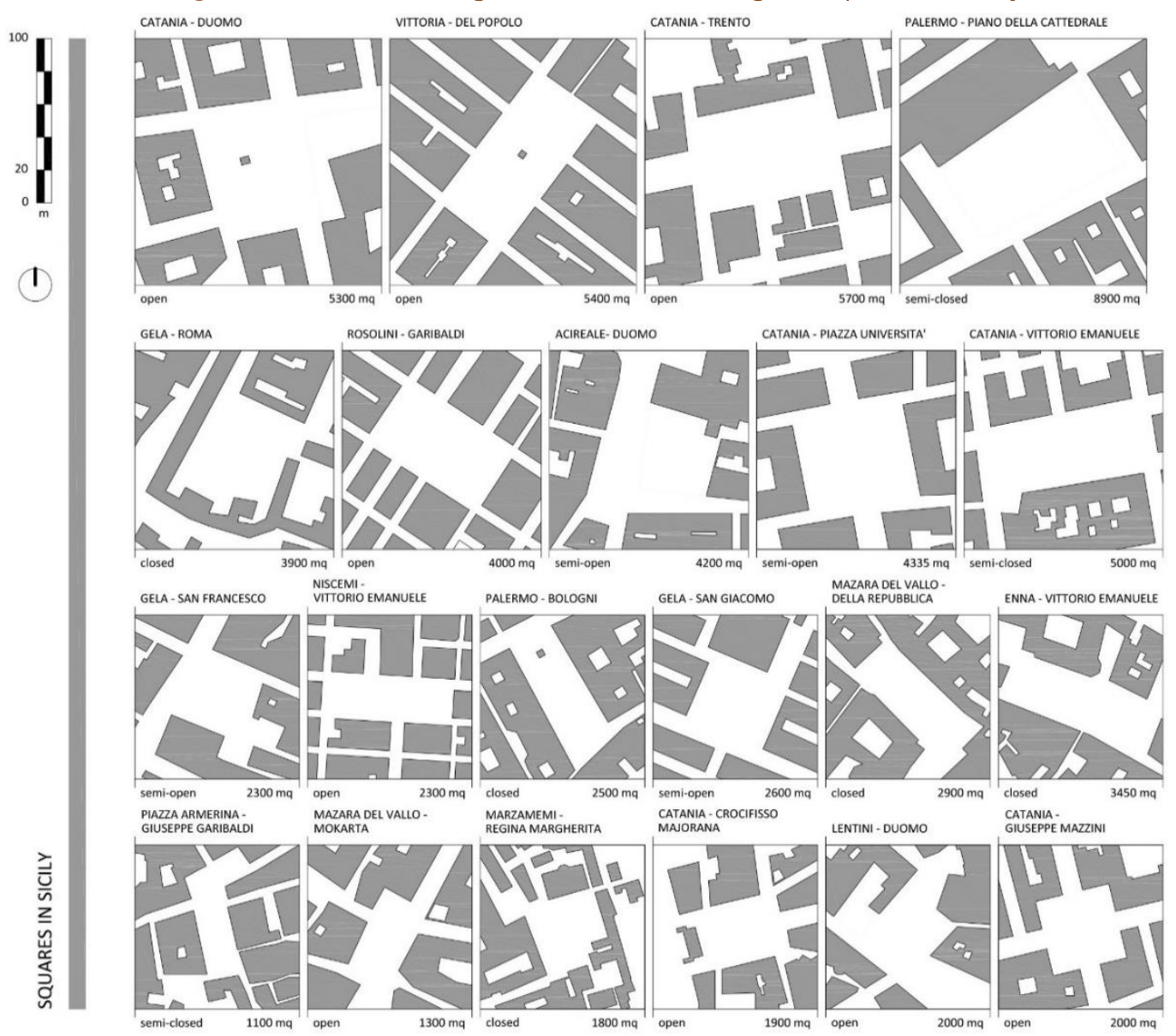

Source: Graphic elaboration by the author

Note: The names, planar dimensions, and spatial opening/closing are indicated in the image

It will be during the Renaissance that the dimensional study of rectangular squares will assume a certain relevance. Since that time many masters of architecture and urban planning have expressed their opinion on what could be the ideal size of a rectangular square, considering the relationship between height and depth: Leon Battista Alberti thought that the height of the building that dominates the square should be between $1 / 3$ and 1/6 of the depth; in the nineteenth century Otto Wagner enlarged the area of the open space to 12 hectares, but Camillo Sitte on the contrary preferred a more compact space, in which the width of the square had to be equal to or double the height of the main building; finally Hermann Maertens chose the height/depth ratio equal to 1/2 or 1/3 (Roseti, 1985).

To make some comparisons between similar and not diametrically different cases, the rectangular squares of Barcelona and Sicily have been divided into different geometric classes. Instead of expressing the dimensional relationship between height and depth in numerical fractions (as in the cases mentioned above), a different classification based on angular widths has been proposed. Once the plan and all sections of the square have been represented, the "altimetric profiles" of the space must be drawn: these paths follow the course of the sections by marking the height of the tallest building along each side. At this point, placing an observer of 1,70 $\mathrm{m}$ at one meter from the perimeter of the square and taking the visual organ as vertex, consider the angle between two half-lines: the first line reaches the height of the opposite higher building; the second one is horizontal and parallel to the ground. As an example, in Figure 3 is reported the dimensional study of two squares analysed 
- Plaza de Josep M. Folch i Torres (Barcelona) and Piano della Cattedrale (Palermo, Sicily) - with the roof plan, the sections and two altimetric profiles. As shown in the image, the angles considered can be very different from one profile to another and sometimes there are evident differences in height between the two opposite sides of the square: this peculiarity has been found many times in Sicilian squares, and often it was due to the presence of an important building whose elevation was much higher than the others.

Figure 3. Dimensional study of two squares with the roof plan
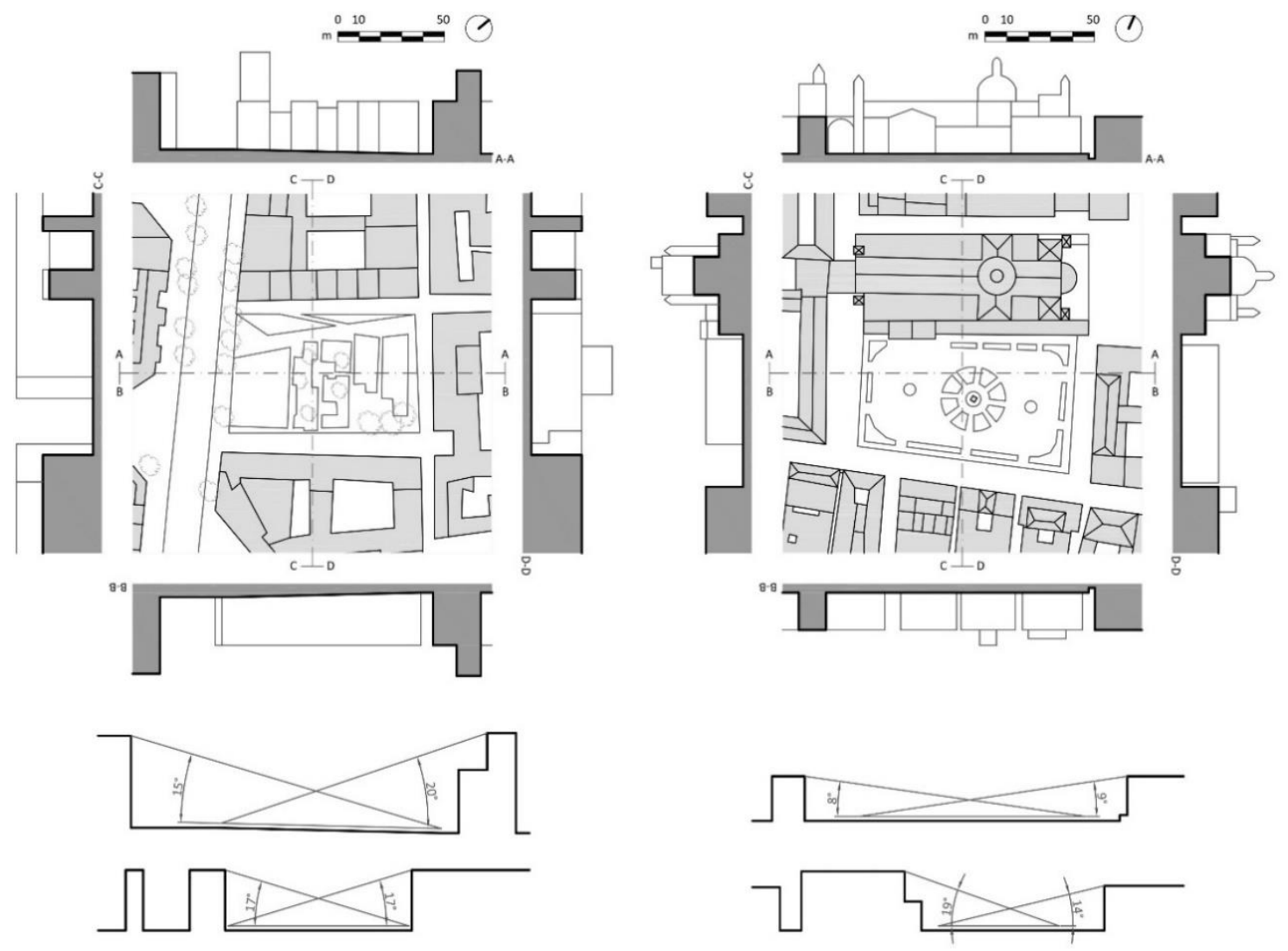

Source: Graphic elaboration by the author.

Note: The sections and the altimetric profiles: on the left is the Plaza de Josep M. Folch i Torres in Barcelona; on the right is the Piano della Cattedrale in Palermo (Sicily)

Based on the drawings of plans and altimetric profiles of many Sicilian and Barcelona squares, the places have been classified into three geometric classes that include all of them. The drawings in Figure 4 describe the method used: to categorize the squares it is necessary to trace the elevation profiles and identify the major angles $\theta_{1}$ and $\theta_{2}$ (they can belong to the short side and the long side, or vice versa); based on the width of these angles, the open space is classified in one of the three categories indicated in the table; to note is the addition of an angle $\theta_{\text {med, }}$ a reference width when the squares have very similar ratios between depth and elevations in the two directions.

Although sometimes it will be difficult to assign a specific category to each square due to its different altitudes, this division is fundamental because the composition of the urban scene changes completely according to the geometric class and, therefore, the light perceived in the space will be different.

ACE, 16 (47) CC BY-ND 3.0 ES | UPC Barcelona, España | From Barcelona to Sicily: An Investigation on the Relationship Between Composition and Daylight in Squares. DOI: http://dx.doi.org/10.5821/ace.16.47.10504 
Figure 4. The geometric classification of rectangular squares
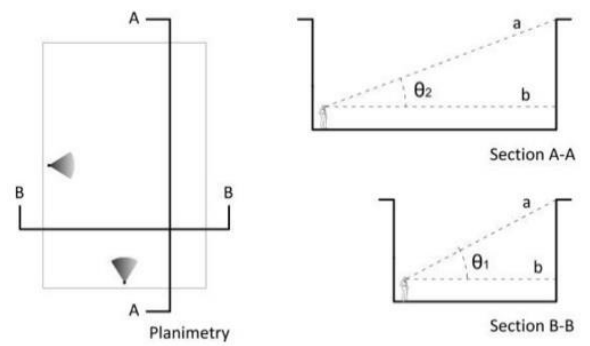

\begin{tabular}{cccc}
\hline Class & Angle $\theta_{1}$ & Angle $\theta_{2}$ & Angle $\theta_{\text {med }}$ \\
\hline 1 & $\theta_{1} \leq 20^{\circ}$ & $\theta_{2} \leq 15^{\circ}$ & $\theta_{\text {med }} \leq 15^{\circ}$ \\
\hline 2 & $20^{\circ}<\theta_{1}<30^{\circ}$ & $15^{\circ}<\theta_{2}<25^{\circ}$ & $15^{\circ}<\theta_{\text {med }}<30^{\circ}$ \\
\hline 3 & $\theta_{1} \geq 30^{\circ}$ & $\theta_{2} \geq 25^{\circ}$ & $\theta_{\text {med }} \geq 30^{\circ}$ \\
\hline
\end{tabular}

Source: Graphic elaboration by the author.

Note: On the left, the determination of the angles $\theta 1$ and $\theta 2$ on the altimetric profiles. On the right, the table showing the widths of the angles and the respective categorization of the squares in three classes

\subsection{Urban scene}

The term "urban scene" is used to indicate a precise view of the city space as it is framed by the observer. To understand the spatial composition of the urban scene, it is necessary to consider the user's visual field and the type of urban space (Lopez-Besora, 2016). Regarding the visual field, its distribution on the vertical plane has been evaluated, excluding the horizontal one, whose limits are difficult to define when the observer moves in the urban environment: in particular, it was considered that the upper and lower limits of the urban scene are those of the visual field central area, which are $30^{\circ}$ above and $40^{\circ}$ below the standard line of vision (Panero and Zelnik, 1996). That said, to simulate the visual scene as it is perceived by the observer, pictures taken with a plausible height from the ground $(1,70 \mathrm{~m})$ were used, with the horizontal axis that is parallel to the floor. The camera body is always placed perpendicular to the ground, in doing so the line of sight remains parallel to the ground: basically, the vision moves little with respect to this line, and the gaze is fixed on the horizontal for most of the time; a person can move the head about 5 degrees up and down to the maximum. These images were analysed to collect data on the light perceived in the squares.

Figure 5. Piazza Duomo in Acireale (Sicily)
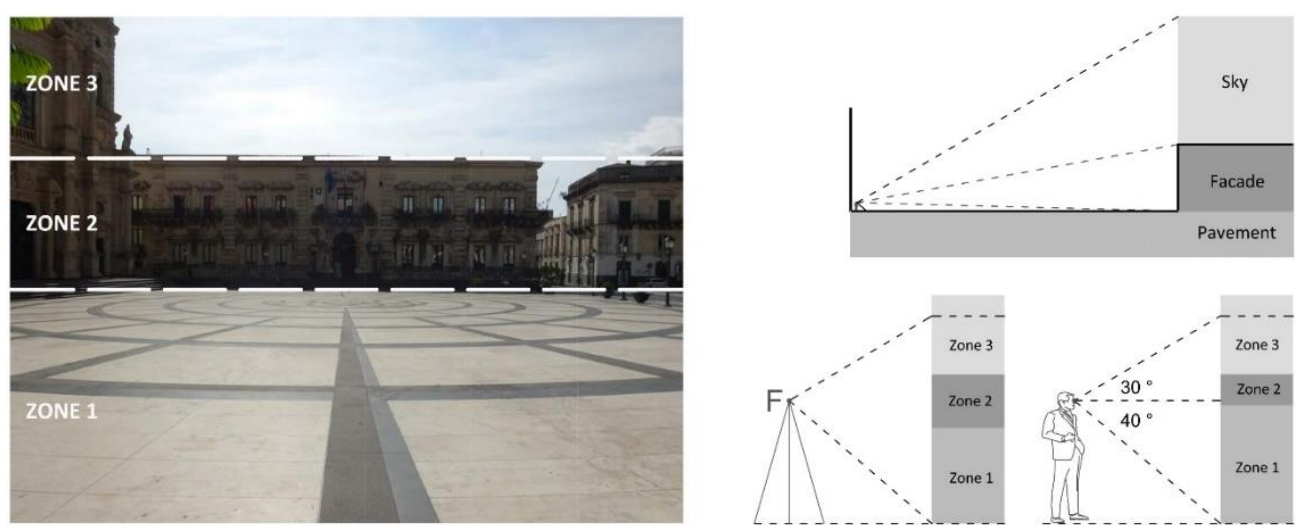

Source: Graphic elaboration by the author.

Note: On the left, the south urban scene $e^{3}$ which is divided into three zones of interest (pavement, facade, sky). On the right, above is a diagram showing the partition of the urban scene, below the distributions of the zones in the field of view of the camera and that of a real observer are compared.

${ }^{3}$ When the expressions "orientation of the facades" and "urban scene" are used in the text, reference is made to their position with respect to the square: if the north urban scene is mentioned, for example, it refers to the view towards the elevations located to the north of the square (which is then the direction of gaze in every photograph), which would be facades facing south.

ACE, 16 (47) CC BY-ND 3.0 ES | UPC Barcelona, España | From Barcelona to Sicily: An Investigation on the Relationship Between Composition and Daylight in Squares. DOI: http://dx.doi.org/10.5821/ace.16.47.10504 
The other important factor to define the spatial peculiarities of the urban scene is the type of built environment and how it is perceived by the observer. To this end, a division into horizontal bands of the scene was used (Lopez-Besora, 2015), distinguishing three different areas of investigation: zone 1 at the bottom (the pavement), often characterized by a certain compositional homogeneity and in which the least dispersions of the illumination values are usually recorded; zone 2, which corresponds to the surface occupied by the facades and which shows the greatest compositional variability and, therefore, the most significant dispersion of luminance values; zone 3, which coincides with the band occupied by the sky, which can show a high variability of measurements based on the position of the sun and the meteorological conditions present on site at the shooting time. This type of division gives a simple but very clear idea of the spatial limits of the square, in fact as stated by Lou Michel: "Urban spatial envelopes are formed by the facades of buildings and pavements describing the outer limits of the void between them. Sometimes urban space is clear and organized, sometimes is not, but for spatial definition it is only necessary to locate those facades or other major surfaces that are prominent enough to be considered dominant boundaries" (Michel, 1995, p. 104).

In any case, the position of each of the bands within the visual scene is always the same, and this allows the extrapolation of this pattern in any type of urban fabric, varying its proportions. Obviously, as shown in Figure 5, there are little differences in the distribution of the limits of the urban space between the real view and the simulated one through the camera: in this case the pavement area increases and that of the facade decreases in the real field of view.

The effectiveness of the method is greater for front views, which is why the rectangular square is the best to this type of evaluation ${ }^{4}$. The percentage distribution of the areas in this type of environments depends on the relationship between the distance of the observer and the height of the facade, which is why the geometric categorization of the rectangular squares proposed before is consistent with this methodology.

In Figure 6 is reported another graphic elaboration where the distribution of the zones of the urban scene according to the angles of geometric classes $\left(\theta_{\text {med }}=15^{\circ}, 25^{\circ}, 35^{\circ}\right)$ is shown. The percentage of the pavement remains unchanged in the three elaborations, since the distance between the observer and the facade is maintained; if the observer's distance from the facade increases, the pavement area would slightly raise, while the other areas would change radically. In any case, Figure 6 permits to understand how the urban scene will be composed in the three geometric classes that have been created.

Figure 6. Percentage of the three zones in the visual field for the three geometric classes
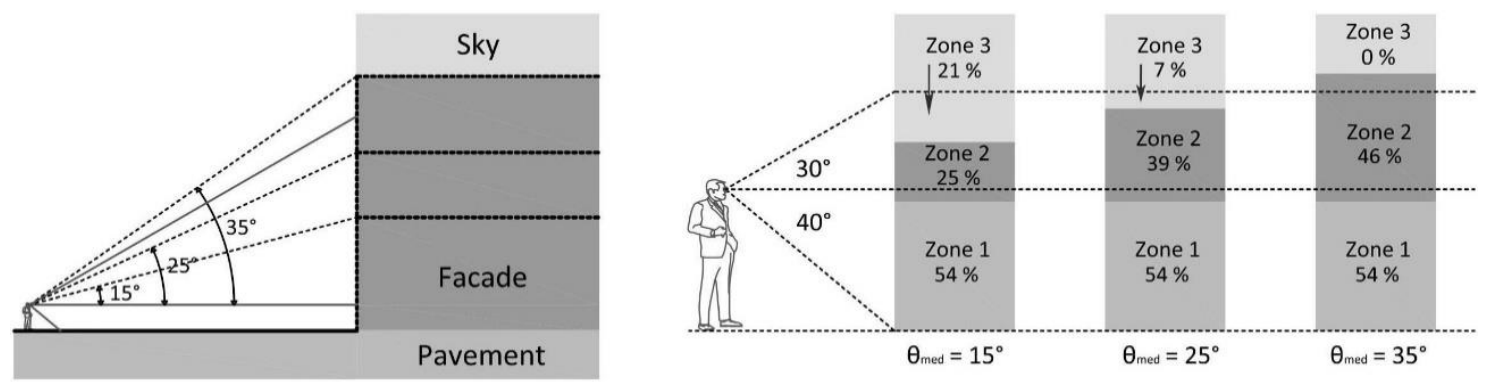

Source: Graphic elaboration by the author

Note: The observer is placed at the same distance from the facade which takes on three different heights.

\footnotetext{
${ }^{4}$ Considering that the experimental software allows to measure the luminance in a rather large area, if it is more distributed on a plane as happens in the visual scene of the rectangular squares, it is possible to minimize the influence of the "surface slant" (Michel, 1995).
}

ACE, 16 (47) CC BY-ND 3.0 ES | UPC Barcelona, España | From Barcelona to Sicily: An Investigation on the 


\subsection{Materials and methods}

As mentioned above, the investigation starts from a specific collection of photographic shots taken in the squares: the fundamental condition is that the three zones of the framed urban scene are easily recognizable. These photographs were made with the following tools:

1. A very common compact camera, a Sony DSC-WX350: a fundamental aspect is that the camera gives the possibility to set three different exposure values $(-2,0,+2)$ for the shot and to set the optical sensitivity and sky conditions.

2. A professional tripod, to position the camera body perpendicular to the ground at a fixed height of $1.70 \mathrm{~m}$ : with this element, the three images with different EV (Exposure Value) can be taken without making the camera move.

The study is based on the luminous information coming from pictures to determine the luminance distribution in the urban scene. There are other commercial software applications that use HDR technology to create luminance maps in false colour from digital pictures. However, in this case it was used a proprietary software developed and checked during a research on daylight in Mediterranean environments (Lopez-Besora, 2015) (Lopez-Besora et al., 2016) because it considers some spatial particularities of the depicted urban scene, such as the defined zones. This digital image processing software analyses the luminosity of each pixel, extracted from the s-RGB information of a JPG image with an exif heading. This information is converted into a number ranging from 0 to 765 which, after calibration and/or numerical processing, is thus converted into luminance values $\left(\mathrm{cd} / \mathrm{m}^{2}\right)$. Compared with other types, this software provides light information about the whole picture and the defined classes that correspond to Zones 1, 2 and 3 in the urban scene. To process the images with the experimental software, it was necessary to prepare a data folder for each urban scene photographed, inside which the three pictures with different exposure in .bmp format must be inserted, together with an input data file and the program's start icon. The following list shows the data series that must be inserted in the input file:

a) The limits of zone 1 and zone 2 of the photographed urban scene, measured in pixels; in this way it is possible to obtain specific lighting data for each area of interest.

b) The technical data of the photographic image: ISO sensitivity, exposure time and F-Stop focal ratio.

c) A maximum reference luminance value.

d) The software also gives the possibility to set the coordinates in pixels of a point or a rectangle of the image in case it is necessary to measure the values of an object or a specific area.

Once the info has been entered correctly and the program has processed the images, there is the possibility to consult a wide range of output data. Unlike other types of software, the experimental software applied here gives information for the whole image or for each zone in which the urban scene is divided, and calculates the average luminance $\left(\mathrm{cd} / \mathrm{m}^{2}\right)$, the standard deviation $\left(\mathrm{cd} / \mathrm{m}^{2}\right)$ and the spatial contrast (unit values) of the photograph. These outputs have been used for the type of analysis described in this article, which, as anticipated, research relationships between the architectural composition of urban squares scenes and their illumination during the day. To address the topic of the analysis of daylight in the architectural space, it is necessary to consider the strong variability of the solar contribution on the surfaces of the space, based on the position of the sun in the celestial vault and on atmospheric conditions. A wise initial composition of the urban environment to better manage daylight is therefore fundamental. In the case of a corrective intervention on an existing space, an in-depth research is required on the architectural elements of the space from a dimensional, material and surface point of view, to record the effect of constantly variable solar lighting on them.

The investigation proposed in this paper considers the high variability of the light contribution during the day: for this reason, more than one photograph of the same urban scene was processed. So, the

ACE, 16 (4.7) CC BY-ND 3.0 ES | UPC Barcelona, España | From Barcelona to Sicily: An Investigation on the 9 Relationship Between Composition and Daylight in Squares. DOI: http://dx.doi.org/10.5821/ace.16.47.10504 
scenes were analysed at three different times of the day: in this way it was possible to observe the net change of data caused by the relationship between the orientation of the facades and the different photo shots. Photographs were taken at each of the following time intervals (GMT+2):

1. $8: 30-11: 30$ (morning).

2. $11: 30-14: 30$ (midday).

3. $14: 30-17: 30$ (afternoon).

The shots were taken in the presence of clear skies or at most partially cloudy. The photographic analysis period lasted from May to October 2019 based on logistical possibilities. During the spring, the urban scenes of the Barcelona squares were collected, after the summer the Sicilian ones. The pictures were taken at one meter from the wall, along the median line of each side of the square and towards the opposite facade, so that frontal perspectives were generated. The squares were chosen so that the realization of the photographs was easy and without impediments: open spaces very crowded with tourists, vehicles and other elements that contrast with the architectural composition of the square have been avoided; obviously, it has not always been possible to respect these parameters, which is why a margin of error must always be taken into consideration in the results achieved by the software. Twelve images have been studied for each square, corresponding to the three-time shots and to the four elevations of the square.

Once all the photographs have been taken and processed by the program, a graphic rendering of the output data was created according to the charts shown in Figure 7, which reports:

a) The subdivision of the image into the three survey zones, indicating the day and time of shooting.

b) A chart with the average luminance of the entire scene (a dashed vertical line), that of the individual zones (recognizable by the light grey backgrounds) and the value of the standard deviation (dark grey segment), all returned in $\mathrm{cd} / \mathrm{m}^{2}$. By analysing the relationship between luminance of two adjacent areas, it is possible to detect the presence of the discomfort glare ${ }^{5}$, which is direct and difficult to manage if it comes from the sun and is instead indirect if due to the reflection of the sun's rays on the pavement or other urban surfaces. In general, it will be considered as annoying a light above $10000 \mathrm{~cd} / \mathrm{m}^{2}$, while glare will begin to be perceived where the difference between the average luminance of two adjacent areas will exceed ten units (Baker and Steemers, 2002), as it happens between zone 3 and zone 2 in Figure 7.

c) Two other charts (expressed in unit values): the first shows the ratio between the standard deviation and the luminance in each single zone, and provides with indicative information on the dispersion of the luminance data (it can indicate the percentage of cast and attached shadow if the difference with the illuminated area is clear); the second shows the trend of spatial contrast, which indicates the areas where the architectural details are most identifiable in proportion to the luminance and the presence of furnishing elements. Spatial contrast is calculated by the software according to the methodology developed by Rockcastle and Andersen (2014). This parameter was developed to provide information about the distribution of light in a digital image. The spatial contrast parameter makes a difference between images with the same average luminance and same standard deviation, but different distribution of brightness areas (or pixels) within the scene. To calculate that, each pixel in the image is compared with the four neighbouring ones and then averaged to produce a local contrast matrix of size. The final percentage is obtained from the ratio between the sum of these local values and a reference maximum. Low percentages correspond to contrasted images with small details in size, that is non-uniform scenes. High percentages correspond to images where similar pixels are close, not dispersed in the scene, thus uniform scenes. The procedure has some limitations related to the

\footnotetext{
${ }^{5}$ In outdoor environments the presence of glare is certainly less frequent than in a transitional space (Araji et al, 2007) (Graziano, 2020). However, if the light present in an environment is excessive, it may not be tolerated by the human eye, becoming a discomfort element. An effect of this type can occur, for example, when smooth surfaces deflect the solar ray towards the observer's eye (Michel, 1995).
}

ACE, 16 (47) CC BY-ND 3.0 ES | UPC Barcelona, España From Barcelona to Sicily: An Investigation on the 10 Relationship Between Composition and Daylight in Squares. DOI: http://dx.doi.org/10.5821/ace.16.47.10504 
quality and resolution of the images, but it is used as an approximation to obtain the contrast of pictures.

Figure 7. Example of the analysis on the perceived light on south urban scene of the Plaza de les Caramelles in Barcelona
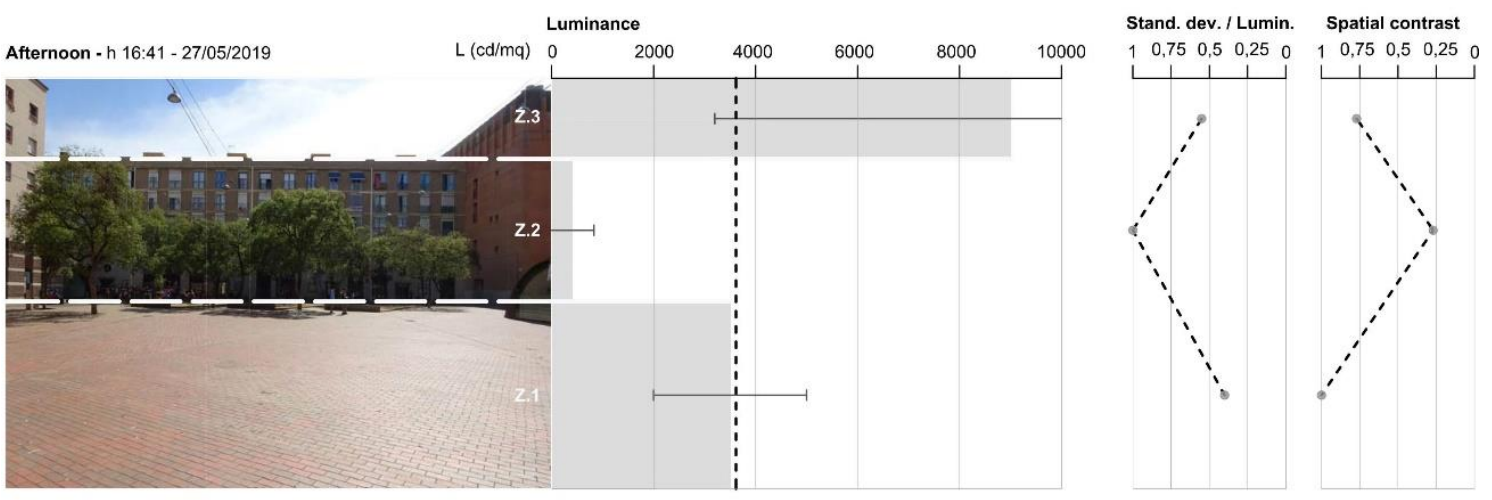

Source: Graphic elaboration by the author.

Note: The image shows the shooting time (GMT+2), the date, the average values of luminance in the zones (on a scale of values in $\mathrm{cd} / \mathrm{m}^{2}$ ranging from 0 to 10000), the ratio between the standard deviation and the luminance values, the spatial contrast of the three zones (both expressed in unit values).

\section{Two case studies: Piazza Università and Plaza de Masadas}

The analysis and its subsequent graphing were performed on a total of twelve cases, of which six from Barcelona and six from Sicily. In this paragraph it is presented a comparison between two squares that were carried out in each place: Piazza Università in Catania (Sicily), latitude $37.50^{\circ} \mathrm{N}$; Plaza de Masadas in Barcelona, latitude $41.40^{\circ} \mathrm{N}$.

In Figure 8 the plans, the sections and the altimetric profiles of the two spaces are inserted. These are two rectangular squares whose facades are almost parallel to the direction of the cardinal axes: this peculiarity makes it easier to examine the relationship between solar exposure and orientation of the facades. The spatial opening/closing aspect is different, as the elevations of Piazza Università are emptied along the south-north axis by a large street (Via Etnea) ${ }^{6}$; on the contrary, Plaza de Masadas can be defined as closed, as the building curtain opens only in one corner of the urban environment.

Piazza Università is one of the most popular public places in the city of Catania: it is surrounded by eighteenth-century buildings, extends over an area of approximately $4300 \mathrm{~m}^{2}$ and is governed by a strong compositional principle based on the search for the symmetry of volumes and furnishing elements. The pavement area is occupied by four streetlamps arranged in pairs in front of the two prominent buildings located east and west of the space; four benches have recently been placed around each streetlamp. The square is also accessible at the corners of the planar rectangular by the four converging streets, narrower than the central crossing. The curtain buildings do not differ much in height, defining visual angles $\theta_{1}=16^{\circ}$ and $\theta_{2}=14^{\circ}$, which insert the square among those belonging to geometric class 1.

\footnotetext{
${ }^{6}$ As can be seen in Figure 2, Piazza Università was considered as a semi-open space. This decision stems from the fact that the building curtain of the square is always open at the corners and even more along the southnorth axis: nevertheless, it was not considered to be completely opened, as the view from the centre of the area towards the corners does not go beyond the square itself, giving an impression of closure in those points according to the principle of "coherence of the view" by Camillo Sitte (2015).
} 
Plaza de Masadas is a small square of $1500 \mathrm{~m}^{2}$ in La Sagrera district: it represents one of the rare cases in Barcelona in which the elevations are perfectly orthogonal to the cardinal directions and one of the few examples of arcaded rectangular squares that can be found in the city. The building curtain is almost completely closed and surrounded by neoclassical buildings of the nineteenth century. Today the square shows itself as a neighbourhood space, frequented by families and at the service of the local community. The architectural composition is very clear and regulated by geometric axiality; benches and trees are placed along the perimeter, leaving free the open space of the square where there is a small circular fountain in the centre. A building curtain of the same height occupies most of the urban scenes in the four directions, which is why the angles $\theta_{1}=18^{\circ}$ and $\theta_{2}=13^{\circ}$ have been considered, placing the square in geometric class 1.

Figure 8. Dimensional study of two squares with the roof plan
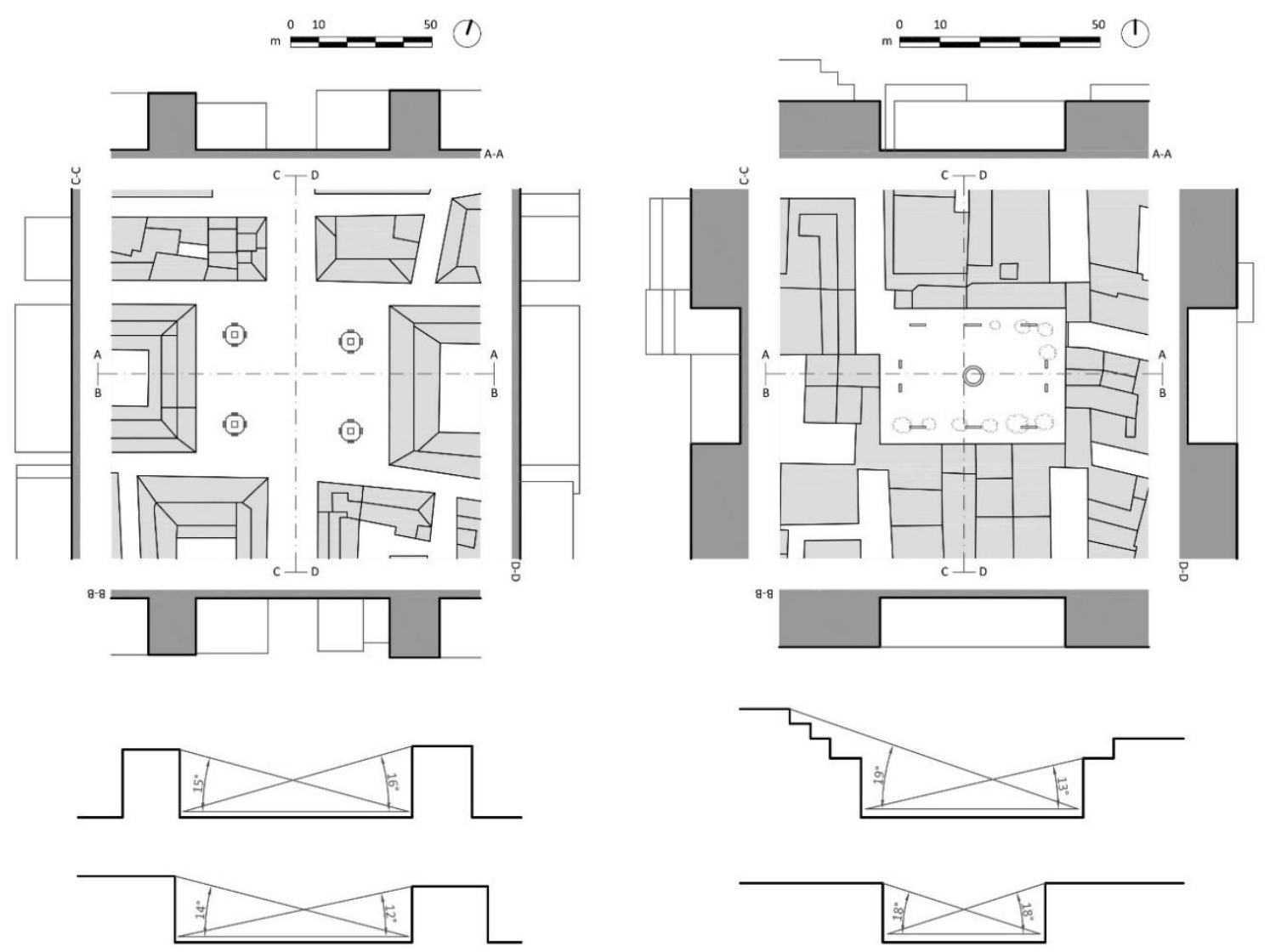

Source: Graphic elaboration by the author.

Note: the sections and the altimetric profiles: on the left is the Piazza Università in Catania (Sicily); on the right is the Plaza de Masadas in Barcelona.

Although the two squares have a very different planimetric extension - as Piazza Università is almost three times larger than the other - what makes the two squares similar and therefore realizes an interesting comparison are the altimetric profiles. Based on this peculiarity and the orientation of the facades, therefore, similar results in the analysis are expected to be found. Figure 9 shows the photographs taken on the two squares, sorted by rows and columns: the first indicate the four cardinal positions of the urban scenes, the second the three intervals of the photographs. 
Figure 9. Urban scenes of Piazza Università (top) and Plaza de Masadas (bottom)
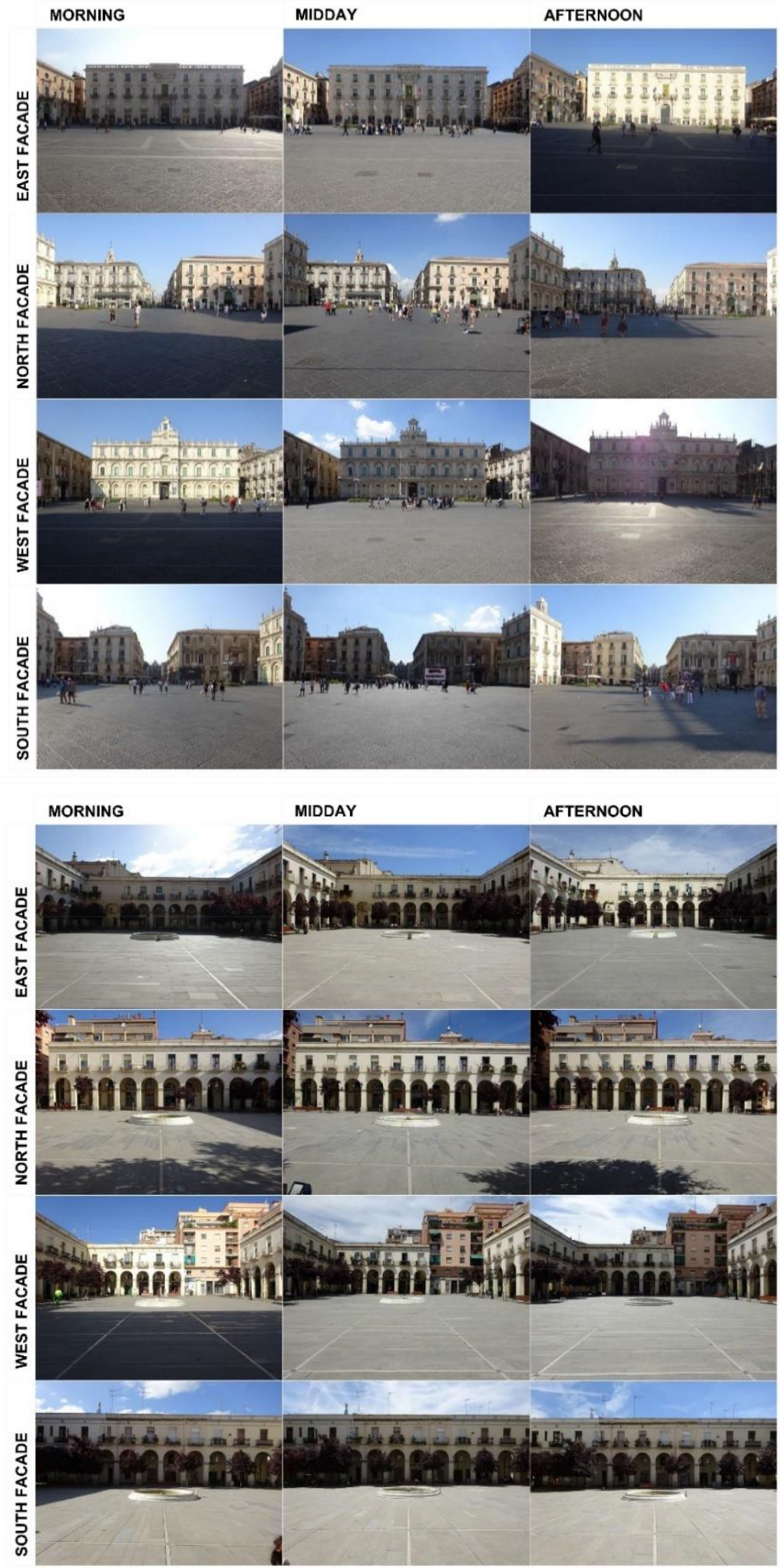

Source: Graphic elaboration by the author. 


\section{Results}

The output data of the daylight analysis are reported in the graphical elaboration of Figures 10 and 11. These summary images show all the data that have been introduced with Figure 7, including the day and time the photographs were taken; the arrangement of the graphs follows the same scheme of the grid with the urban scenes of Figure 9. As regards the survey on Piazza Università, the data collected were very coherent with the compositional development and the spatial reading of the square, highlighting the characteristics of axiality and symmetry of the place.

Figure 10. Results of the average perceived luminance, standard deviation and spatial contrast for each zone of the urban scenes of Piazza Università in Catania

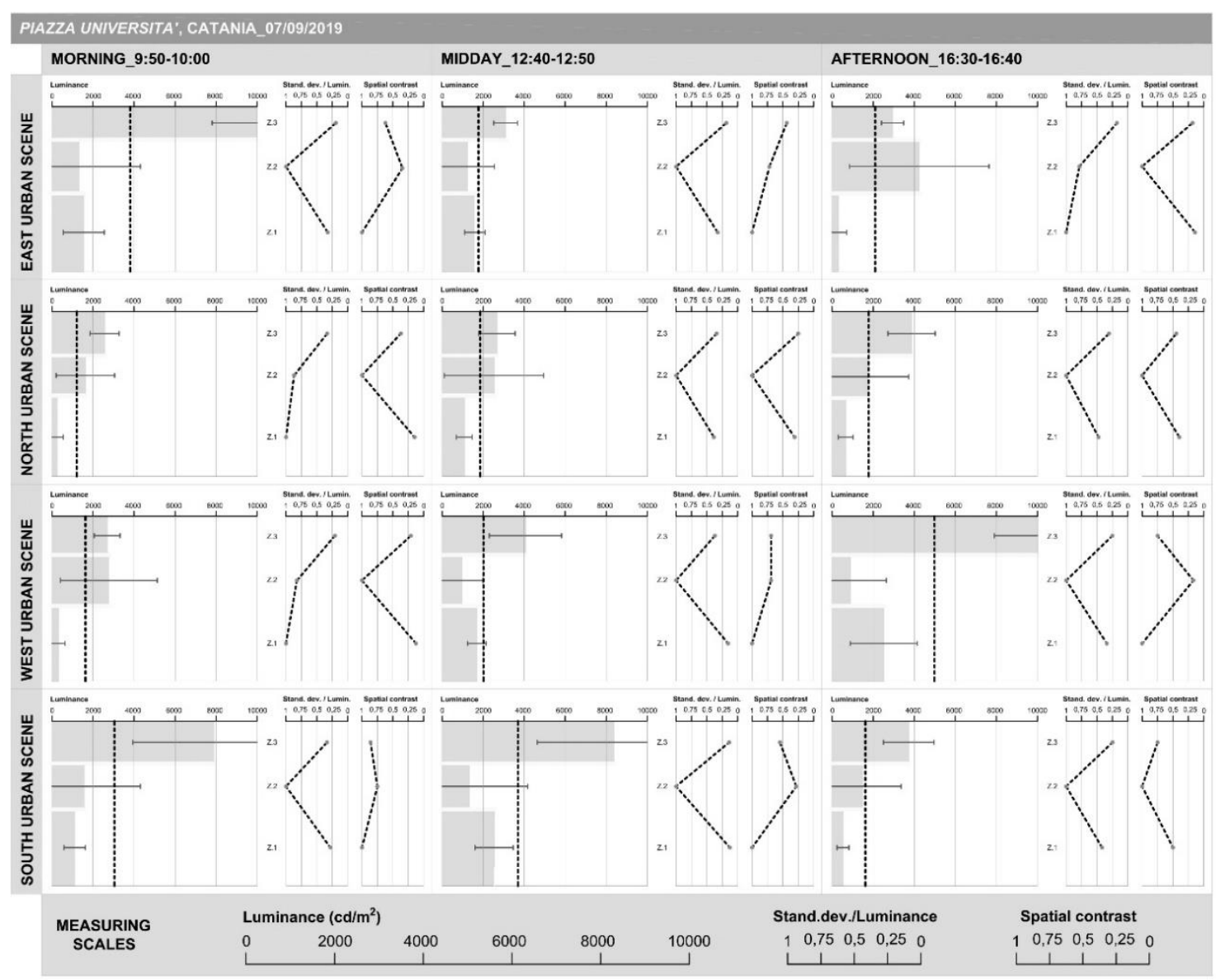

Source: Graphic elaboration by the author.

With reference to the results in Figure 10, the following considerations can be advanced:

- In the east and west urban scenes, it can be seen how the distribution of the luminance bands, the trend of the charts on the standard deviation and the spatial contrast are almost specular. This peculiarity is essentially due to three factors: the path of the sun, the orientation of the square and the almost symmetrical architectural composition of these two fronts of the square. To the east in the morning and to the west in the afternoon the sun is low and can enter the field of vision causing direct glare and a backlight effect. Average luminances in zone 3 of 13000$15000 \mathrm{~cd} / \mathrm{m}^{2}$ have been recorded, which are about 10 times those of zone 2 of the facades. Glare by reflection, on the other hand, is partly mitigated by the absorption of the solar radiation by 
the dark lava stone paving, which lowers the average luminance of zone 1 with a maximum of $2500 \mathrm{~cd} / \mathrm{m}^{2}$. To the east in the afternoon and to the west in the morning, on the other hand, the facades become the brightest and most contrasted areas: this happens due to the shadow in the foreground that is projected from the building behind the observer, making zone 1 the area with the greatest ratio between standard deviation and average luminance.

- The data of the north and south scenes, underline the interpretation of this square: it is more a space of passage than of rest. The direction along the Via Etnea is emphasized by contrast with the elevation of buildings, and by the luminance of zone 2 always higher than the pavement (the only exception is the south urban scene at midday), thus indicating its movement towards the south-north axis; the dark projection of the shadow on the floor seems to contribute to this perceptual condition, positioning itself parallel to Via Etnea and indirectly indicating its direction.

Now, comparing the results of the Piazza Universita with those of the Plaza de Masadas in Figure 11, some interesting reflections emerged, which can be summarize as follow:

- Considering that in the east and west urban scenes of the Catalan square, zone 3 occupies a greater area than the Sicilian one, a higher average luminance was obtained. As it happened in Piazza Università, the east urban scene in the morning is very contrasted. The luminance obtained in zone 2 was 25 times lower than that of the sky $\left(19000 \mathrm{~cd} / \mathrm{m}^{2}\right)$ and 10 times lower than that of the pavement: this condition can generate glare both direct and indirect. In this case, the presence of some thin clouds in front of the sun contributes to create a bright area in this zone of the sky that increases light contrast.

- The distribution of most of the other data is very similar between the two squares, except for the lower luminance of the sky in the west view (due to the buildings in zone 3) and the lower dispersion of values in zone 1 to the east (based on the non-identical shooting time and the consequently absence of cast shadow).

- The clearest scene (average $\left.\mathrm{cd} / \mathrm{m}^{2}\right)$ in Piazza Università is the west urban scene $\left(>5000 \mathrm{~cd} / \mathrm{m}^{2}\right)$ in the afternoon. In the Plaza de Masadas it is the east one $\left(>8000 \mathrm{~cd} / \mathrm{m}^{2}\right)$ in the morning. In both cases the sun is quite perpendicular to the facade and illuminates it intensely. On the contrary, the darkest scene in both cases is the north urban scene $\left(<2000 \mathrm{~cd} / \mathrm{m}^{2}\right)$ in the morning.

- Regarding the north and south urban scenes, there is a similar trend in the graphs of standard deviation and spatial contrast, but very different in the distribution of the luminance bands due to the geometric-compositive characteristics of the squares and pavement materials. In particular, the light grey limestone rock used to pave the Catalan square reflects a great deal of light, and the average luminance of zone 1 is always higher than that of zone 2, approaching 6000 $\mathrm{cd} / \mathrm{m}^{2}$ in the north urban scene at midday; as mentioned above, this is not the case for the Sicilian square because of the dark grey lava stone which absorbs a lot of light and makes the pavement not very bright.

- $\quad$ The C-shaped pattern defined by the standard deviation/luminance is fulfilled in all cases except when there are very marked shadows on the ground of the urban scenes (west and north ones in the morning and east one in the afternoon in Piazza Università; west urban scene in the morning in Plaza de Masadas). In general, there is a very similar behaviour.

- The spatial contrast pattern is replicated in a similar way in both cases, according to the urban scenes and times of the day. In the case of Barcelona, the values in Zone 2 are usually lower than in Sicily, which indicates less fragmentation of the image on small, lightly contrasted surfaces. As spatial contrast evaluates the distribution of light and dark zones according to the pixels in an image, this parameter is sensitive to the resolution and distance of the analysed elements.

- In general terms, the visual scenes analysed in Barcelona offer higher average luminance values than in the case of Catania, especially in the pavement area. Comparing the two graphs, it is possible to see that the average value of the whole scene and those of each single zone follow this trend. Slight differences in terms of their altimetric profiles and the surface characteristics of the materials in facades and pavements explain this fact. 
Figure 11. Results of the average perceived luminance, standard deviation and spatial contrast for each zone of the urban scenes of Plaza de Masadas in Barcelona

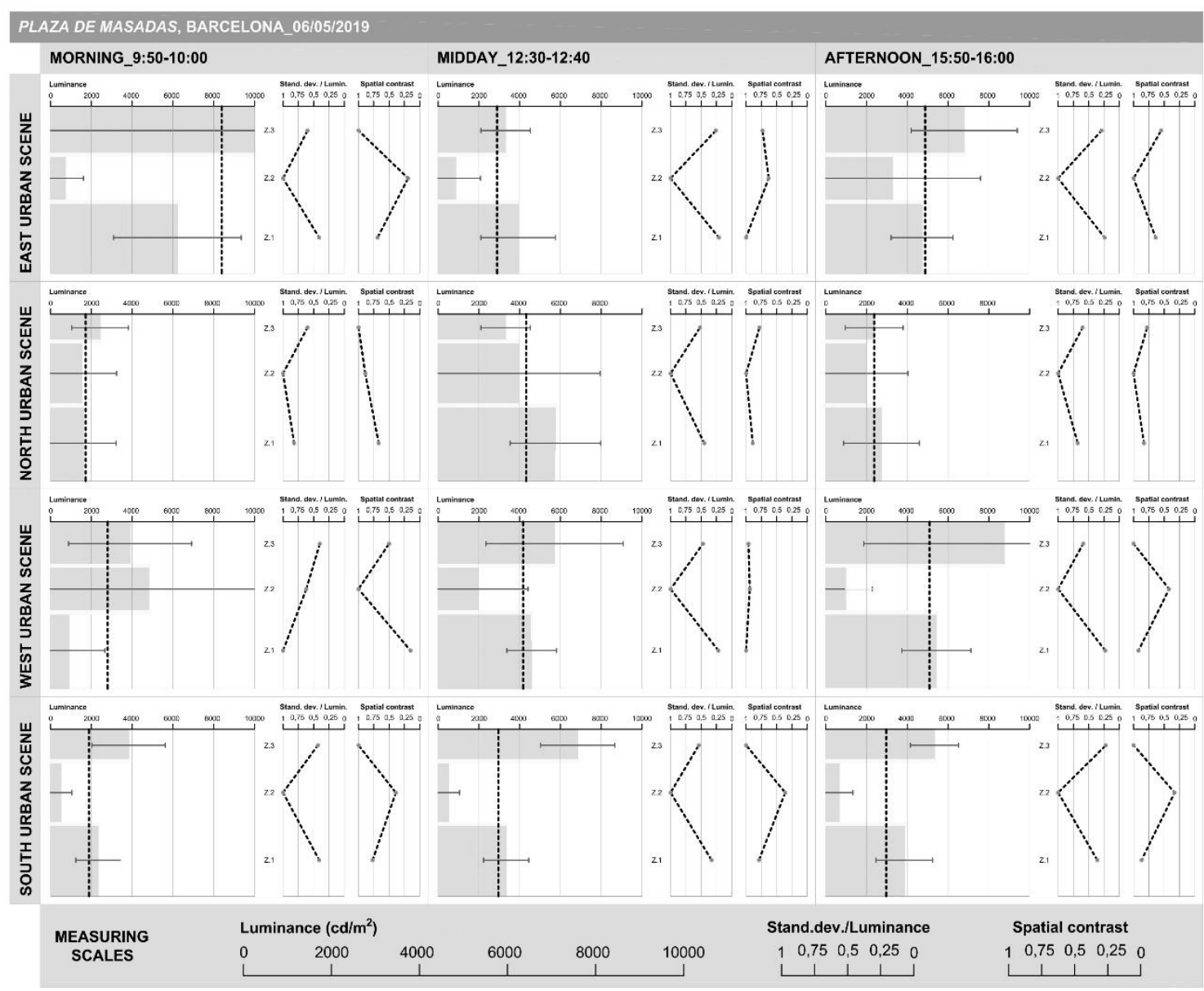

Source: Graphic elaboration by the author.

\section{Conclusions}

The study of natural elements has once again become strategic for the design of open places (Berizzi, 2018). The research described in this contribution considers daylight as an impalpable object that can enormously condition the liveability of the exterior space. That said, architectural design cannot neglect the study of daylight as a tool for the rigorous composition of the open environment and the urban visual scene. Relating the path of the sun with the architectural work is of primary importance for the purpose of understanding the impact of light on the surfaces of the environment and the repercussions on visual and thermal comfort for the users; the east-west orientation compared to the north-south one changes the perception of the environment, generating more illuminated and heated spaces than others. Alongside these types of reflections, it should be noted that most outdoor activities require a suitable contribution of light, both from a functional and biological point of view.

Through the investigation covered in this article, it was sought the relationship between design choices and the perception of urban space in the case of rectangular squares in Mediterranean cities. The technical assessment of daylight provides a series of data on the environment that can be used 
for urban redevelopment works or as a support for the architectural composition of new spaces. The data obtained from the analyses suggest a series of simple design criteria based on the different spatial compositions and dimensional categories to which the squares belong.

It was reported one comparison between two cases of the geometric class 1, rectangular squares, through which it was possible to draw some conclusions regarding this specific category. The squares of this class are obviously the brightest ones based on the dimensional ratio between heights and depths which facilitates a great exposure to solar radiation. In the case of an orthogonal orientation of the facades with respect to the cardinalities, the probability that the sun enters the visual field looking south, east and west increases: in the latter two cases the inclination of the solar rays can be close to the horizontal line of vision, respectively during the early morning and late afternoon, causing direct or indirect glare. Excessive luminance contrast is measured between zones 3 and 2 in the east and west urban scenes: these phenomena can be mitigated by the use of different reflectivity materials in pavements and facades with a targeted purpose.

In the specific case of the two squares analysed (Piazza Duomo and Plaza de Masadas), the data collected on the perceived daylight, together with the geometric characteristics, the architectural composition, the finishing materials, the orientation of the facades and the position of street furniture, provide further food for thought. All these elements affect the visual and thermal comfort of users wishing to stop or cross the place. Regarding the Sicilian square, the time spent in the space is proportional to the distribution of shadows on the walking surface. The liveability of the environment is higher in the morning on the east side and in the afternoon on the west side, when the dark projection invades the place, and this concerns both moving users and those sitting on the benches (as documented by photographs on site). Lingering in these areas of the square at these time intervals ${ }^{7}$ means a more favourable microclimate, no discomfort glare and a better view of the architecture on the opposite side because it is more contrasted. At midday, the square becomes a place of passage only, as the absence of shelter from the sun considerably reduces thermal comfort. Nevertheless, the visual comfort is quite good for two reasons: the south-north crossing or vice versa ensures that the sun being close to the line of vision, thus avoiding direct glare; the dark lava stone absorbs most of the solar radiation and there is no glare by reflection. As far as the square in Barcelona is concerned, the most comfortable areas in the morning and in the afternoon are the same (considering the similar geometric characteristics of the two urban spaces), but the situation at midday is different: in this case, there is the possibility of using the porticoed corridors around the perimeter of the square, which allow people to stay even during the hottest hours of the day; the visual comfort is good, but the lighter ground makes the facades less contrasting, so it is always advisable to have a darker pavement which offers a better visual perception of the architectural environment.

To conclude, the survey presented here adds one more aspect to the study of squares from the morphological point of view and stands as a supporting investigation on the relationships between daylight and urban space. Furthermore, the analysis methodology that was described is not limited to the sole evaluation of the squares. By providing a correct interpretation of the various urban scenes, the evaluation criterion can also apply to other sites in the public space. Through a series of studies like this, it is possible to understand the perceptual peculiarities of the urban environment and consequently improve the spatial quality of inhabited centres.

\footnotetext{
7 Please note that the time intervals referred to are those described in paragraph "2.3 Materials and methods": 8:30-11:30, morning; 11:30-14:30, midday; 14:30-17:30, afternoon.
}

ACE, 16 (4.7) CC BY-ND 3.0 ES | UPC Barcelona, España | From Barcelona to Sicily: An Investigation on the 17 Relationship Between Composition and Daylight in Squares. DOI: http://dx.doi.org/10.5821/ace.16.47.10504 


\section{Acknowledgments}

This research has been supported by the Spanish Ministry of Economy under project code BIA20167765-R.

\section{Authorship}

The first author has developed the research, analyzed the data and written the work. Second, third and fifth authors have conceptualized and designed the research, and have revised the text. The fourth author has developed the software and has analyzed the results of the research.

Conflict of interests: The authors declare that there is no conflict of interest.

\section{References}

Araji, M.T.; Boubekri, M., \& Chalfoun, N. (2007). An Examination of Visual Comfort in Transitional Spaces. Architectural Science Review, 50(4), 349-356. DOI: https://doi.org/10.3763/asre.2007.5042

Baker, N.V., \& Steemers, K. (2002). Daylight Design of Buildings: A Handbook for Architects and Engineers, London: Routledge.

Berizzi, C. (2018). Piazze e spazi collettivi. Nuovi luoghi per la città contemporanea. Padua: Il Poligrafo.

Graziano, M. (2020). Transizione spaziale e percezione della luce. Phd Kore Review, 13-14, pp. 39-49.

Lam, W.M.C. (1992). Perception and Lighting as Formgivers for Architecture. New York: Van Nostrand Reinhold.

Lopez-Besora, J. (2015). La llum mediterrània i els espais d'accés a l'arquitectura (PhD thesis). UPC, Barcelona. Retrieved from https://upcommons.upc.edu/handle/2117/96022

Lopez-Besora, J.; Isalgue, A., \& Coch, H. (2016). A digital image processing method for urban scenes brightness assessment. ACE: Architecture, City and Environment, 11(32), 157-170. DOI: https://doi.org/10.5821/ace.11.32.4837

Lopez-Besora, J.; Serra-Coch, G.; Coch, H., \& Isalgue, A. (2016). Daylight Management in Mediterranean Cities: When Shortage Is Not the Issue. Energies, 9(9), 753, 1-12. DOI: https://doi.org/10.3390/en9090753

Mancuso, F., \& Kowalski, K (2007). Squares of Europe, Squares for Europe. Places d'Europe, Places pour Europe. Cracow: Jagiellonian Univerity Press.

Michel, L. (1995). Light: The shape of space. Designing with space and light. New York: John Wiley \& Sons Inc.

Rockcastle, S., \& Andersen, M. (2014). Measuring the dynamics of contrast \& daylight variability in architecture: A proof-of-concept methodology. Building and Environment, 81, 320-333. DOI: https://doi.org/10.1016/j.buildenv.2014.06.012 
Panero, J. and Zelnik, M. (1996). Las dimensiones humanas en los espacios interiores. 7th edition. Barcelona: Gustavo Gili.

Portoghesi, P. (1990). La piazza come "luogo degli sguardi". Rome: Gangemi.

Romano, M. (2015), La piazza europea. Venice: Marsilio.

Roseti, C. (1985). Il progetto della piazza. Rome: Gangemi.

Rubert de Ventós, M. (2007), No square, no city. La place fait la ville. In F. Mancuso and K. Kowalski. (Eds.), Squares of Europe, Squares for Europe. Places d'Europe, Places pour Europem (pp. 59-66). Cracow, Poland: Jagiellonian University Press.

Sitte, C. (2015), L'arte di costruire le città. L'urbanistica secondo i suoi fondamenti artistici. (2nd edition). Milan: Jaca Book.

Tuzi, S. (1990). L'idea di piazza nella cultura classica. In P. Portoghesi. (Ed.), La piazza come "luogo degli sguardi" (pp. 229-241). Rome, Italy: Gangemi.

Wolfrum, S. (2014). Squares: Urban Spaces in Europe. Basel: Birkhauser Architecture. 